\title{
EFFECT OF AQUEOUS EXTRACT OF ALLIGATOR PEPPER (ZINGIBERACEAE AFRAMOMUM MELEGUETA) ON GESTATIONAL WEIGHT GAIN
}

\author{
U. INEGBENEBOR*, M. I. EBOMOYI ${ }^{2}$ K. A. ONYIA ${ }^{1}$, K. AMADI, and A. E. \\ AIGBIREMOLEN ${ }^{2}$
}

Department of Physiology, College of Medicine, Ambrose Alli University, Ekpoma, Edo State, Nigeria. druteinegbenebor@yahoo.com, *Correspondence author

Department of Physiologyl, School of Basic Medical Sciences, College of Medicine, Benin City, Edo State, Nigeria

Department of Pharmacology ${ }^{2}$, College of Medicine, Ambrose Alli University, Ekpoma, Edo State, Nigeria

\begin{abstract}
Summary: Increased gestational weight gain is associated with higher rates of complications of pregnancy and delivery. Gestational weight gain of $9-12 \mathrm{Kg}$ has been associated with the best outcome for both mothers and infants. However, weight gain in most pregnant women is not within this range, perhaps due to the difficulty of calculating the exact quantity, timing and duration of dietary restriction in individual patients that would bring their weight gain within the normal range. There is therefore a need to develop a drug or food supplement that would reduce weight gain without causing adverse effects on the fetus. Aframomum melegueta is widely used in Nigeria by most people including pregnant women for various purposes. It is against this background that the present investigation examines the possibility of its beneficial effects on pregnancy, using Sprague Dawley rat as the animal model. Twenty female and ten male Sprague-Dawley rats of proven fertility from a pilot study were randomly mated in groups of two females and one male. Three days later, female rats in the experimental groups were given intra-peritoneal injections of $0.5 \mathrm{mg}, 1 \mathrm{mg}, 1.5 \mathrm{mg}$ and $2 \mathrm{mg}$ of aqueous extract of alligator pepper respectively while the control had $2 \mathrm{ml}$ of distilled water.. All rats were observed for 18-25 days. There was a significant $(\mathrm{P}<0.05)$ reduction in gestational weight gain of the experimental rats. The litters were not adversely affected. It is suggested that the active component of aqueous extract of alligator pepper be determined because of its beneficial effect of gestational weight gain reduction.
\end{abstract}

Key words: Gestational weight gain, Aqueous Extract, Intra-peritoneal injection, Alligator Pepper, Nutrition.

\section{Introduction}

In a study on Gestational weight gain and pregnancy outcome in obese glucose tolerant women, it was found that birth weight increased significantly with increasing weight gain, which was associated with significantly higher rates of hypertension, caesarean section, induction of labor and large for gestational age infants. It was suggested that minimal gestational weight gain might normalize birth weight.(Jensen et al., 2005) However, weight gain reduction in pregnancy had been used in the United States of America before 1960 in an attempt to reduce pregnancy complications and improve maternal and fetal outcome with controversial results, largely due to low birth weight. ( Abrams et al., 2000) Further studies showed that pregnancy weight gain within the Institute of Medicine's (IOM) recommended range $(9-12 \mathrm{Kg})$ was associated with the best outcome for both mothers and infants. However, weight gain in most pregnant women is not within the IOM's range, (Abrams et al., 2000) perhaps due to the difficulty of calculating the exact quantity, timing and duration of dietary restriction in individual patients that would bring their gestational weight gain within the normal range. There is therefore a need to develop a drug or a food supplement that would reduce gestational weight gain without causing adverse effects on the fetus.

Alligator pepper is widely used by many cultures in Nigeria for various purposes. It is used for entertainment, where it is served along with Kola nuts, for religious rites by diviners attempting to invoke spirits and priests of the Iyayi (Faith) Society of Nigeria, who serve alligator pepper along with kola nuts to believers as communion. It is also an ingredient in pepper soup, a spicy delight in parts of WestAfrica.(Personal observation) The constituents of the essential oil, extracted from 
Alligator pepper include humulene, caryophyllene, their oxides, and nonterpenoids. (Ajaiyieoba \& Ekundayo, 1999) Pregnant women are not excluded from eating this widely used substance. It is against this background that the present investigation examines the possibility of beneficial effects of Aframomum melegueta on pregnancy, using Sprague-dawley rat as the animal model.

\section{Materials and method}

\section{Pilot Study}

Eighteen (18), six months old adult male and 36, six months old female Sprague-dawley rats of the same strain; each weighing $125 \mathrm{~g}$, were obtained from the Animal House, College of Medicine, Ambrose Alli University, Ekpoma, Edo State, Nigeria. The rats were kept in standard cages in a well ventilated room for acclimatization, for a period of two weeks during which, normal rat chow and clean drinking water were given to the rats $a d$ libitum.

After the acclimatization period, a pilot study was carried out thus; thirty six (36) female rats were randomly allocated to eighteen cages (A-S) so that there were two female rats in each cage. Thereafter, eighteen male rats were randomly allocated to the eighteen cages containing the female rats so that each cage then contained one male rat and two female rats. After three days, during which mating was expected to have occurred between the male and the female rats, the males were separated from the females and labeled, MA, MB ...to MS, depending on which of the cages A to $S$, they had been previously placed. The females were then put in separate maternity cages and labeled $A_{1}, A_{2}, B_{1}, B_{2} ; \ldots$ to $S_{1}, S_{2}$ depending on which of the cages $A$ to $S$, they had been previously placed. The female rats were observed for 18 to 25 days in their separate maternity cages. Both male and female rats continued to be fed with rat chow and clean drinking water ad libitum throughout the duration of the experiment. After delivery, the female rats were allowed to breastfeed their litters for three weeks before being selected for the experimental study.

\section{Selection of Rats for Experimental Study}

The selection of rats for the experimental study was based on the pregnancy outcome of the pilot study as shown in Table 1. Twenty female and ten male Sprague dawley rats of proven fertility were selected based on the following criteria; all fertile females $\left(B_{1}, C_{1}\right.$, $D_{1}, E_{1}, E_{2} ; F_{1}, F_{2} ; G_{1}, I_{1}, I_{2}, J_{1}, J_{2}, K_{I}, L_{2}, M_{1}$, $\mathrm{M}_{2}, \mathrm{~N}_{2}, \mathrm{P}_{1}, \mathrm{Q}_{2}, \mathrm{R}_{2}$ and males (ME, MF, MI,
MJ and MM), which successfully impregnated both of their partners as well as (MC, MD, $\mathrm{MK}, \mathrm{MP}$ and MQ ), whose partners $\left(\mathrm{C}_{1}, \mathrm{D}_{1}\right.$, $\mathrm{K}_{1}, \mathrm{P}_{1}$, and $\mathrm{Q}_{2}$ delivered a higher number of liters than those (B1, G1, L2, N2 and R2) of $\mathrm{MB}, \mathrm{MG}, \mathrm{ML}, \mathrm{MN}$ and $\mathrm{MR}$

\section{Experimental Animals}

Twenty female and ten male Sprague dawley rats of proven fertility (as observed in the Pilot Study) were used for this study. The rats were then eight months old and were kept in cages in a well ventilated laboratory. The rats were fed with normal rat chow and clean water ad libitum.

Preparation of Aqueous extract of Alligator pepper

Twenty milligrams $(20 \mathrm{mg})$ of granulated alligator pepper was mixed with $20 \mathrm{ml}$ of distilled water and was allowed to stand for 2 hours. Thereafter, the mixture was filtered with a filter paper into a clean beaker.

Quantification of Aqueous extract of Alligator pepper

Since $20 \mathrm{ml}$ of aqueous extract was obtained from $20 \mathrm{mg}$ of granulated Alligator pepper, I $\mathrm{ml}$ of aqueous extract is obtainable from $1 \mathrm{mg}$ of granulated Alligator.

The twenty selected female rats of proven fertility from the pilot study were randomly allocated into five groups 1, 2, 3, 4 and 5. Each group, which consisted of four female rats, was kept in two separate cages so that there were ten cages (1A, 1B; 2A, 2B; 3A, 3B; 4A, 4B; and $5 \mathrm{~A}, 5 \mathrm{~B})$ for the five groups. Group 1 was labeled as the Control group while groups 2, 3, 4 , and 5 were labeled as the Experimental groups. The ten selected male rats of proven fertility from the pilot study were randomly allocated to the ten cages containing five groups of female rats so that each cage contained two female rats and one male rat. They were left in their various cages for three days in order to allow mating to occur. After three days, males were withdrawn from the females. The male rats were put in separate cages labeled $\mathrm{M}_{1} \mathrm{~A}, \mathrm{M}_{1} \mathrm{~B}, \mathrm{M}_{2} \mathrm{~A}, \mathrm{M}_{2} \mathrm{~B}, \mathrm{M}_{3} \mathrm{~A}$, $M_{3} B, M_{4} A, M_{4} B$ and $, M_{5} A, M_{5} B$, based on the group each male rat mated with.

The female rats were also separated into different cages so that each female rat occupied a separate maternity cage. The female rats were then labeled in such a way that female rats in the various groups $1,2,3,4$, and 5 became $1 \mathrm{~A}_{1}, 1 \mathrm{~A}_{2}, \mathrm{IB}_{1}, \mathrm{IB}_{2} ; 2 \mathrm{~A}_{1}, 2 \mathrm{~A}_{2}$, $2 \mathrm{~B}_{1}, 2 \mathrm{~B}_{2} ; 3 \mathrm{~A}_{1}, 3 \mathrm{~A}_{2}, 3 \mathrm{~B}_{1}, 3 \mathrm{~B}_{1} ; 4 \mathrm{~A}_{1}, 4 \mathrm{~A}_{2}, 4 \mathrm{~B}_{1}$, $4 \mathrm{~B}_{2}$ and $5 \mathrm{~A}_{1}, 5 \mathrm{~A}_{2}, 5 \mathrm{~B}_{1} 5 \mathrm{~B}_{2}$ respectively. Each female rat then weighed $150 \mathrm{~g}$. 
Effect of Alligator pepper on Gestational Weight Gain

\section{Administration of Distilled Water to the Control group \\ The female rats in the control group $\left(1 \mathrm{~A}_{1}\right.$,} $1 \mathrm{~A}_{2}, \mathrm{IB}_{1}, \mathrm{IB}_{2}$ ) were fed with normal rat chow and clean drinking water ad libitum throughout the duration of the experiment. They were administered intra-peritoneal injection of $2 \mathrm{ml}$ of distilled water. Aqueous extract of Alligator pepper was not administered to the female rats in the control group. They were observed in their separate maternity cages for 18 to 25 days.

Administration of Aqueous Extract of Alligator Pepper to the Experimental Groups

Soon after the males were withdrawn from the females, the female rats in the Experimental groups were given intraperitoneal injections of various doses of aqueous extract of Alligator pepper as shown in Table 2. The doses were selected using the toxic doses observed by Igwe et al. as a benchmark. ( Igwe et al, 1999). The rats in the experimental groups were fed with normal rat chow and clean drinking water throughout the duration of the experiment. They were also observed for 18 to 25 days in their separate maternity cages.

\section{Measurement of Weight of Litters}

A transparent plastic dish was placed on a top loading balance. The meter of the top loading balance was then reset at zero. All litters from a particular rat were placed into the plastic dish and their total weight was recorded. The mean weight of litters from a particular rat was calculated by dividing the total litter weight by the number of litters.

Data Analysis was done using cross tabulation, bar chart and Daniel Soper's free software for calculating One Way Analysis of Variance (ANOVA) at 5\% level of significance. (Soper, 2009)

\section{Results}

The results of the effect of aqueous extract of Alligator pepper on pregnancy outcome in Sprague dawley rats are as shown in Table 2. There was a significant difference in weight gain between female rats in the control and experimental groups 2, 3, 4 and 5 $(\mathrm{P}=0.002, \quad 0.001, \quad 0.0001$ and 0.001$)$ respectively. There was no weight gain in female rats that did not litter.

Except for group 5 with average litter weight of $4.55 \mathrm{~g}$ in the experimental group, the average weight of litters was within close range, (5.305.56)g. It should be noted that apart from the significant $(\mathrm{P}=0.0001)$ lower birth weight of the off-springs from Experimental group 5, the mean birth weights of off-springs of other rats $(5.50 \mathrm{~g}, 5 . .40 \mathrm{~g}$ and $5.35 \mathrm{~g})$ in the experimental groups 2, 3, 4 were not significantly different ( $\mathrm{P}=0.77 ; 0.27$ and 0.20 respectively) from that of the controls $(5.53 \mathrm{~g})$.

Table 2: Effect of Aqueous Extract of Alligator pepper on Gestational weight gain and Birth weight of Litters in Rats $n=$ no of rats that littered in the group, $*=$ Statistically significant

\begin{tabular}{|c|c|c|c|c|c|c|c|c|c|}
\hline Group & Status & 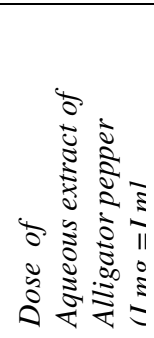 & 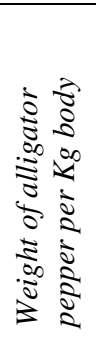 & 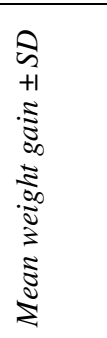 & $\begin{array}{l}P \text { - } \\
\text { value }\end{array}$ & 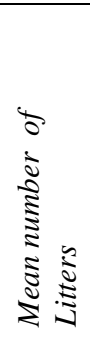 & $\begin{array}{l}\vdots \\
\vdots \\
\vdots \\
\vdots \\
0 \\
0 \\
0 \\
0 \\
0 \\
\vdots \\
\vdots \\
\vdots \\
\vdots \\
0 \\
0\end{array}$ & 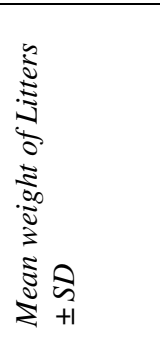 & $P$-value \\
\hline $1(n=4)$ & $\begin{array}{l}\text { Control } \\
\text { rats }\end{array}$ & Nil & Nil & $\begin{array}{l}187.5 \\
\pm 31.82\end{array}$ & & 9 & 24 days & $5.53 \pm 0.13$ & \\
\hline $2(n=3)$ & $\cong$ & $0.5 \mathrm{mg}$ & $\begin{array}{l}3.3 \\
\mathrm{mg}\end{array}$ & $75 \pm 0$ & $\begin{array}{l}0.002 \\
*\end{array}$ & 6 & 23 days & $5.50 \pm 0.12$ & 0.77 \\
\hline $3(n=3)$ & 吾 & $1.0 \mathrm{mg}$ & $\begin{array}{l}6.7 \\
\mathrm{mg}\end{array}$ & $50 \pm 0$ & $\begin{array}{l}0.001 \\
*\end{array}$ & 7 & 23 days & $5.4 \pm 0.15$ & 0.27 \\
\hline $4(n=4)$ & 离 & $1.5 \mathrm{mg}$ & $\begin{array}{l}10 \\
\mathrm{mg}\end{array}$ & $75 \pm 0$ & $\begin{array}{l}0.000 \\
*\end{array}$ & 9 & 24 days & $5.35 \pm 0.21$ & 0.20 \\
\hline $5(n=3)$ & 爻 & $2.0 \mathrm{mg}$ & $\begin{array}{l}13.3 \\
\mathrm{mg}\end{array}$ & $50 \pm 0$ & $\begin{array}{l}0.001 \\
*\end{array}$ & 11 & 23 days & $4.55 \pm 0.17$ & $0.0001 *$ \\
\hline
\end{tabular}


Table 1: Selection of Rats for Experimental Study

\begin{tabular}{|c|c|c|c|c|c|}
\hline $\mathrm{S} / \mathrm{N}$ & $\begin{array}{l}\text { Female } \\
\text { Rat }\end{array}$ & $\begin{array}{l}\text { Male } \\
\text { Partner }\end{array}$ & Duration of Pregnancy & $\begin{array}{l}\text { No of Litters } \\
\text { delivered }\end{array}$ & SELECTION \\
\hline 1. & A1 & MA & NIL & NIL & \\
\hline 2. & A2 & MA & NIL & NIL & \\
\hline 3. & B1 & MB & 23 DAYS & 5 & BI SELECTED \\
\hline 4. & B2 & MB & NIL & NIL & \\
\hline 5. & $\mathrm{C} 1$ & $\mathrm{MC}$ & 23 DAYS & 6 & CI MC SELECTED \\
\hline 6. & $\mathrm{C} 2$ & $\mathrm{MC}$ & NIL & NIL & \\
\hline 7. & D1 & MD & 24 DAYS & 6 & D1 MD SELECTED \\
\hline 8. & D2 & MD & NIL & NIL & \\
\hline 9. & E1 & $\mathrm{ME}$ & 23 DAYS & 5 & E1, ME SELECTED \\
\hline 10. & $\mathrm{E} 2$ & $\mathrm{ME}$ & 23 DAYS & 7 & E2, ME SELECTED \\
\hline 11. & $\mathrm{~F} 1$ & $\mathrm{MF}$ & 25 DAYS & 6 & F1, MF SELECTED \\
\hline 12. & $\mathrm{~F} 2$ & $\mathrm{MF}$ & 25 DAYS & 7 & F2, MF SELECTED \\
\hline 13. & G1 & MG & 23 DAYS & 5 & G1 SELECTED \\
\hline 14. & $\mathrm{G} 2$ & MG & NIL & NIL & \\
\hline 15. & H1 & MH & NIL & NIL & \\
\hline 16. & $\mathrm{H} 2$ & MH & NIL & NIL & \\
\hline 17. & I1 & MI & 23 DAYS & 5 & I1, M1 SELECTED \\
\hline 18. & $\mathrm{I} 2$ & MI & 23 DAYS & 6 & 12, M1 SELECTED \\
\hline 19. & JI & MJ & 24 DAYS & 7 & J1, MJ SELECTED \\
\hline 20. & $\mathrm{~J} 2$ & MJ & 25 DAYS & 8 & J2, MJ SELECTED \\
\hline 21. & K1 & MK & 23 DAYS & 7 & K1, MK SELECTED \\
\hline 22. & $\mathrm{~K} 2$ & MK & NIL & NIL & \\
\hline 23. & L1 & ML & NIL & NIL & \\
\hline 24. & L2 & ML & 23 DAYS & 4 & L2 SELECTED \\
\hline 25. & M1 & MM & 24 DAYS & 6 & M1, MM SELECTED \\
\hline 26. & M2 & MM & 24 DAYS & 8 & M2, MM SELECTED \\
\hline 27. & N1 & $\mathrm{MN}$ & NIL & NIL & \\
\hline 28. & $\mathrm{~N} 2$ & $\mathrm{MN}$ & 25 DAYS & 5 & N2 SELECTED \\
\hline 29. & $\mathrm{O} 1$ & MO & NIL & NIL & \\
\hline 30. & $\mathrm{O} 2$ & MO & NIL & NIL & \\
\hline 31. & $\mathrm{P} 1$ & MP & 23 DAYS & 8 & P1, MP SELECTED \\
\hline 32. & $\mathrm{P} 2$ & MP & NIL & NIL & \\
\hline 33. & Q1 & MQ & NIL & NIL & \\
\hline 34. & Q2 & MQ & 24 DAYS & 6 & Q2, MQ SELECTED \\
\hline 35. & $\mathrm{R} 1$ & MR & NIL & NIL & \\
\hline 36. & $\mathrm{R} 2$ & MR & 23 DAYS & 5 & R2 SELECTED \\
\hline
\end{tabular}

\section{Discussion}

Researchers have found that Alligator pepper has over 27 constituents, which are mainly humulene, caryophyllene and the oxides of these derivatives. (Ajaiyieoba and Ekundayo, 1999) The active agent among these derivatives could not be determined, hence the need to use whole seeds of Alligator pepper in experiments determining the effect of Alligator pepper on pregnancy. However, there were doubts at the beginning of this research work on whether the rats would actually eat rat chow mixed with Alligator pepper. This necessitated the use of intraperitoneal injection of aqueous extract of Alligator pepper. Bolus consumption of 350 $\mathrm{mg}$ of Alligator pepper causes blurring of vision. (Igwe et al., 1999) This dose of Alligator pepper was therefore used as a bench mark. Three hundred and fifty milligrams (350 $\mathrm{mg}$ ) of Alligator pepper in a $50 \mathrm{~kg}$ woman translated to 7 milligrams per Kilogram (7 $\mathrm{mg} / \mathrm{Kg}$ ) body weight. Approximately 6.7 $\mathrm{mg} / \mathrm{Kg}$ body weight was therefore used as the 50 percentile dose for the experiment. The range was therefore made to be between 3.3 $\mathrm{mg} / \mathrm{Kg}$ bodyweight to $13.3 \mathrm{mg} / \mathrm{Kg}$ body weight. None of the rats had serious side effects with the range of doses used. However, as seen in Table 2, there was a significant reduction in gestational weight-gain of the rats $(\mathrm{P}<0.05)$ in the experimental groups, when compared to that in the control group irrespective of the dose that was used. The average weight gain in human pregnancy is about 12.5 Kg.( Milller, 2007) The gestational weight gain in rats was $175-200 \mathrm{~g}$ in the control group and $50-75 \mathrm{~g}$ in the experimental groups.

The weight gain is not only due to the products of conception but also increased water, lipid and protein retention.( Milller, 2007) This was the case in this experiment as the weight gain was in excess of the total birth 
Effect of Alligator pepper on Gestational Weight Gain

weight of litters in the control group.

Reduction in gestational weight gain, in the experimental group, could have been due to the loss of appetite that followed the intraperitoneal injection, or a diuretic effect of the caryophyllene component of Alligator pepper. Placebo effect was ruled out in this study by the intra-peritoneal administration of $2 \mathrm{ml}$ of distilled water to the rats in the control group. The actual cause of weight gain reduction is subject to further studies with better facilities.

It should be noted that the reduction in weight gain did not adversely affect the weight of the litters in the experimental group. It is believed that the aqueous extract of Alligator pepper did not affect the morphology, genetic or reproductive capability of the off-springs of the rats in the experimental group as they were apparently normal and were able to reproduce effectively in a follow up study, which is not presented here. It should be noted that there was a dose dependent and progressively significant decrease in birth weight of offsprings of the experimental rats from $5.50 \mathrm{~g}$ in group $2(\mathrm{p}=0.77)$ to $4.55 \mathrm{~g}$ in group 5. $(\mathrm{p}=0.0001)$ as shown in Table 2 .

It should also be noted that the rats, which had $2 \mathrm{mg}$ of aqueous extract of Alligator pepper had the highest mean number of offsprings (11) with mean birth weight of $4.55 \mathrm{~g}$. However, the birth weights of babies in multiple gestation are usually lower than those in singleton pregnancies.( Bush \& Pernoll, 2007)

Weight gain in excess of $0.75 \mathrm{Kg}$ per week may be predictive of pre-eclampsia. ( Bush \& Pernoll, 2007) Blood pressure measurement was beyond the scope of this study. Diagnosis of pre-eclampsia is based on elevation of blood pressure and proteinuria.

Since gestational weight gain above 12 $\mathrm{Kg}$ is related to higher rates of adverse maternal and fetal outcome ((Jensen et al., 2005), and dietary restriction during pregnancy has led to a slightly increased rate of perinatal mortality, (Abrams et al., 2000) it is suggested that further research, if ethically permissible, should be done to determine if gestational weight gain could be reduced to the acceptable IOM's range, using individualized doses of the aqueous extract of Alligator pepper.

\section{Conclusion}

Intra-peritoneal injection of low doses ( $\leq 13.3 \mathrm{mg} / \mathrm{Kg}$ body weight) of aqueous extract of Alligator pepper (Aframomum melegueta) causes reduction in gestational weight gain in female Sprague dawley rats. It is suggested that the active component of aqueous extract of Alligator pepper be determined. Blood pressure measurements may be included in further studies on the gestational weight gain reduction in order to determine the possible use of aqueous extract of alligator pepper in the prevention of pre-eclampsia in pregnant women.

\section{Acknowledgements}

We are grateful to Vivian Onolemhenmhen, Beatrice Oaikhena, Fortune Ehiagwina and Mary Jane Erhiagbor, who assisted with the day to day activities of this study.

\section{References}

Abrams, B., Altman, S. L. and Pickett, K. E.(2000). Pregnancy weight gain: still controversial. American Journal of Clinical Nutrition. 71(5): 1233S-1241s.

Ajaiyieoba, O.E and Ekundayo, O. (1999). Essential oil constituents of Aframomum melegueta (Roscoe) K. Schum. seeds (alligator pepper) from Nigeria. Flavour and Fragrance Journal. 1999; 14(2): 109111.

Bush, M.C. \& Pernoll, M. L. (2007) Multiple Pregnancy. In: Decherney, A.H., Nathan L. Goodwin, T. M., Laufer, N. Eds. Current Diagnosis and Treatment Obstetrics and Gynecology. 10th Edition. McGrawHill. New York. 301-310.

Igwe S.A.; Emeruwa I.C.; Modie J.A. (1999). Ocular toxicity of Afromomum melegueta (alligator pepper) on healthy Igbos of Nigeria. Journal of Ethnopharmacology. Elsevier. 65(3):203-206.

Jensen, D. M., Ovesen, P., Beck-Nielsen. H., Molsted-Pedreson,L., Sorenson, B., Vinter, C. Damm P.(2005). Gestational weight gain and pregnancy outcome in 481 obese glucose tolerant women. Diabetic Care. 28(9):2118-2122.

Milller D. A. (2007).Hypertension in Pregnancy. Decherney, A.H., Nathan L. Goodwin, T. M., Laufer, N. Eds. Current Diagnosis and Treatment Obstetrics and Gynecology. 10th Edition. McGrawHill. New York. 318-327.

Soper, D. (2009). One-Way ANOVA Calculator (From Summary Data). Free Statistics Calculators Website -Home. www.danielsoper.com. Accessed: 14 December 2009.

Received: September 1, 2009

Accepted: December 18, 2009 